Fifth International Conference on Sustainable Construction Materials and

Technologies. http://www.claisse.info/Proceedings.htm

\title{
DEVELOPMENT AND VERIFICATION OF NEUTRALIZATION DEPTH AND CHLORIDE ION PENETRATION DEPTH MEASUREMENT METHOD USING FIBRESCOPE
}

\author{
Shunsei Tanaka ${ }^{1}$, Yuya Sakai ${ }^{2}$ \\ ${ }^{1}$ Department of Civil Engineering, The University of Tokyo, Hongo 7-3-1, Bunkyo-ku, Tokyo \\ 113-8654, Japan. Email: <shtanaka@iis.u-tokyo.ac.jp>, ${ }^{2}$ Institute of Industrial Science, The \\ University of Tokyo, Komaba 4-6-1, Meguro-ku, Tokyo 153-8505, Japan. Email: \\ <ysakai@iis.u-tokyo.ac.jp>
}

\begin{abstract}
A method to measure the neutralization depth and chloride ion $\left(\mathrm{Cl}^{-}\right)$penetration depth was investigated by drilling a hole with a diameter of 1 or $2 \mathrm{~mm}$ onto a concrete surface and observing the interior by inserting a fibrescope with a diameter of $0.6 \mathrm{~mm}$. This method was intended as a semi-destructive test with high accuracy and minimum damage, which avoids aesthetic defects to the concrete structure. During the measurement, to visualize the neutralization depth or $\mathrm{Cl}^{-}$penetration depth, a phenolphthalein solution or silver nitrate solution was sprayed onto the drill hole. The effect of the extent of the drill hole surface's drying and the spraying amount of solutions on the clarity of coloration with a phenolphthalein solution or silver nitrate solution were investigated. It was found that it is preferable that the concrete surface is sufficiently dry for a clear coloration by a phenolphthalein solution, and it is preferable that the concrete surface is wet for the clear coloration with silver nitrate solution, although the spraying amount did not make much difference on the coloration by both colour indexes. A comparison with the results obtained through measurements using calipers on the cut surface reveals that the proposed method is highly reliable.
\end{abstract}

Keywords: Semi destructive test, Neutralization depth, Chloride ion penetration depth, Coloration, Fiber scope, Drilling.

\section{INTRODUCTION}

The neutralization of covering concrete increases the corrosion rate of the rebar in a reinforced concrete structure. The ingress of $\mathrm{Cl}^{-}$into the concrete also causes rebar corrosion because the passive film of the rebar is destroyed when the concentration of $\mathrm{Cl}^{-}$at the position of the rebar increases. A typical on-site measurement of the neutralization depth or $\mathrm{Cl}^{-}$penetration depth is implemented by observing the colour change when an indicator is sprayed onto the cross section of a $10 \mathrm{~cm}$ core specimen, the split surface of the core specimen, or the chipping surface. Note that $1 \%$ of phenolphthalein solution, which is an indicator of the neutralization depth measurement, gives a red-purple colour to non-neutralized concrete, and remains colourless in 
neutralized concrete (JIS A 1152; RILEM, 1988). And $0.1 \mathrm{~mol} / \mathrm{L}$ of a silver nitrate solution, which is an indicator of the $\mathrm{Cl}^{-}$penetration depth measurement, gives a white colour to concrete containing $\mathrm{Cl}^{-}$, and a yellow-brown colour to concrete that does not contain $\mathrm{Cl}^{-}$(Otsuki et al., 1993). Although what can be observed by spraying the silver nitrate solution is not the $\mathrm{Cl}^{-}$ concentration, but rather the penetration depth of $\mathrm{Cl}^{-}$, numerous studies have been conducted on the $\mathrm{Cl}^{-}$concentration at the boundary whitened by the silver nitrate (Kim et al., 2007; Aoki et al., 2008; He et al., 2011; 2012). Hence, it is possible to estimate the $\mathrm{Cl}^{-}$concentration in concrete when the position of the whitening boundary has been obtained. However, the sampling of a core specimen or the chipping of the surface requires time and effort to transport heavy equipment, install scaffolds, fill up the drill hole, or repair the surface after inspection. Moreover, another problem is that the sampling of a core specimen or the chipping of the surface causes damage and aesthetic defects to the structure and carries the risk of cutting the rebar. For example, in the case of inspecting buildings with high historical value or asset value, it is required to minimize damage to the structure. Thus, measuring methods that suppress damage as much as possible have been investigated.

As an example, a drill method has been proposed, wherein a drill with a diameter of $10 \mathrm{~mm}$ is used to drill the concrete surface. Additionally, drilling powder is caught using a filter paper impregnated with a phenolphthalein solution. Subsequently, the neutralization depth is measured by observing the colour change on the filter paper (Kasai et al., 1998; Nihira et al., 2004; Sawamoto et al., 2010). Here, from the viewpoint of suppressing damage to the structure, a further reduction of the drill hole is desired. Additionally, an advantage is expected, whereby the reduction of the hole diameter makes the filling of the holes easier owing to the reduction of the drill hole volume. However, in principle, it is difficult to reduce the diameter of the drill hole in the drill method because a certain amount of drilling powder is required to ensure the drill method's accuracy.

Additional examples of semi-destructive methods include methods that directly observe the coloration by the indicator on drill hole surface using an endoscope (Harada et al., 2007; Yamamoto et al., 2009) or a stick scanner (Ito et al., 2007; Harada et al., 2009; Zacoeb et al., 2012). In the stick scanner method, it is difficult to reduce the diameter of the drill hole because of the difficulty entailed in developing a smaller stick scanner with precision instruments. However, it is still possible to reduce the diameter of the drill hole in the endoscope method, because endoscopes with a diameter of $0.35 \mathrm{~mm}$ have already been used in the medical field (Kothari et al., 2006). In previous studies, wherein the endoscope method was used to measure the neutralization depth, the smallest drill diameter was $5 \mathrm{~mm}$ (Yamamoto et al., 2007). Moreover, there is room to further reduce drill hole. To achieve the reduction of drill hole, it is necessary to create conditions such that the clear colouring by the indicators occurs on the drill hole surface, because the colouring state of the drill hole's interior cannot be visually confirmed from the surface. It has been reported that the drying extent of the surface and the method of cleaning before spraying the phenolphthalein solution or silver nitrate solution affects the vividness of colouring and the occurrence of colour blur on the surface of a core specimen (Izumi et al., 1988; Aoki et al., 2013). However, in the case of measuring with a drill hole, knowledge does not exist with regard to factors that affect colour vividness or colour blur occurrence on the drill hole surface, when the indicators are sprayed.

Therefore, in this study, an investigation was carried out with the objective of establishing a method to measure the neutralization depth and $\mathrm{Cl}^{-}$penetration depth using drill holes with a diameter of 1 or $2 \mathrm{~mm}$.

First, by using the cutting surface of the specimen, the performance of the coloration applied by the indicators under various conditions was investigated. Additionally, appropriate conditions of the drying extent of the surface, and the indicator amount needed for the neutralization depth measurement and $\mathrm{Cl}^{-}$penetration depth measurement, were confirmed. Next, a process was investigated to ensure that appropriate conditions are applied on the 1 or 2 $\mathrm{mm}$ drill hole surface. Finally, the neutralization depth and $\mathrm{Cl}^{-}$penetration depth were measured by observing a drill hole of 1 or $2 \mathrm{~mm}$ using a fibrescope, and the specimens were cut along the drill hole to measure the neutralization depth and $\mathrm{Cl}^{-}$penetration depth by observing the 
coloration on the cutting surface. By comparing both results, the accuracy of the proposed method was verified.

\section{EQUIPMENT}

In this study, a flexible fibrescope $\left(\phi 0.6 \mathrm{~mm} ; 200 \mathrm{~mm} ; 70^{\circ} ; 4.5 \mathrm{k}\right.$; Kuroda Optnics INC., Japan) with a diameter of $0.6 \mathrm{~mm}$ was used (Figure 1a). A light source device was built in the handle part, and light could be provided from the tip of the insertion part through the optical fibre embedded in the insertion part. The $1 \mathrm{~mm}$ drill and $2 \mathrm{~mm}$ drill shown in Figure $1 \mathrm{~b}$ were used to excavate the surface of the concrete and mortar. The drill holes were cleaned by a brush with a bristle width of $1.27 \mathrm{~mm}$ until the aggregate was clearly visible upon being observed using the fibrescope.

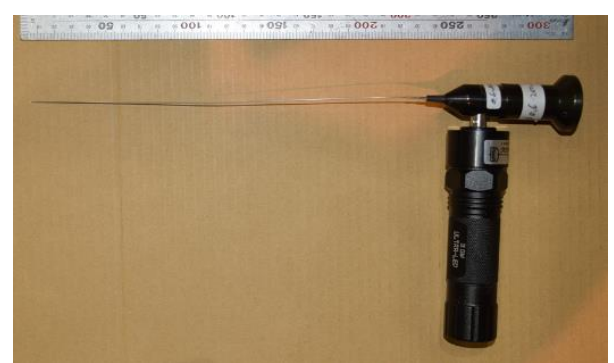

a) Overview of fibrescope

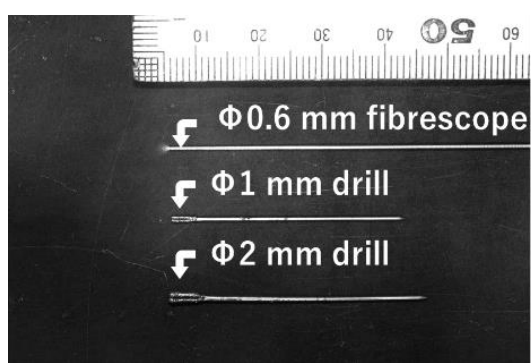

b) Drills and fibrescope

Figure 1. Fibrescope and drill

\section{Measuring coloration boundary depth}

When the boundary of the coloration applied by the spraying indicator was observed in the fibrescope's field of view, the neutralization depth or the $\mathrm{Cl}^{-}$penetration depth was calculated with a resolution of $0.5 \mathrm{~mm}$ using the following equation:

$$
d_{c}=d_{i}+y
$$

where $d_{c}$ is the neutralization depth $(\mathrm{mm})$ or $\mathrm{Cl}^{-}$penetration depth $(\mathrm{mm}) ; d_{i}$ is the insertion depth of the fibrescope $(\mathrm{mm})$, when the coloration boundary is observed in the field of view; $y$ is the distance from the tip of the fibrescope to the coloration boundary $(\mathrm{mm})$. Additionally, $y(\mathrm{~mm})$ was determined as follows. Figure 2a shows the geometry when a fibrescope with a diameter of $0.6 \mathrm{~mm}$ was inserted into a drill hole with a diameter of $2 r \mathrm{~mm}$. Let us assume that the object on the drill hole appears at the position of $x$ within the circular field of view, when the light leaving the object location passes through the fibrescope lens at an angle of $\theta^{\circ}$. Moreover, $x[-]$ is the distance from the centre normalized by the field of view radius. Then, the following relationship holds between $r, y, \theta$, and $x$ :

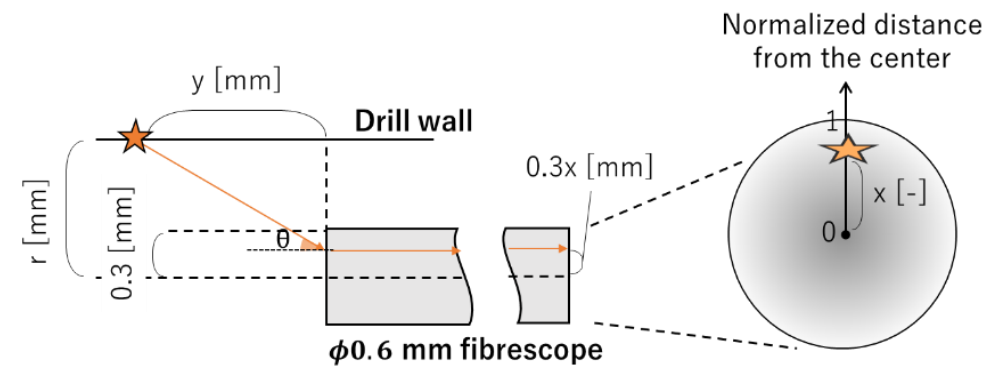


a) Geometry of fibrescope and drill wall

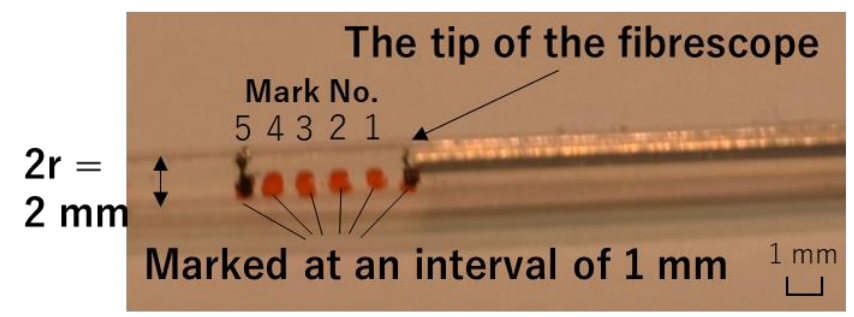

b) Tube with marks

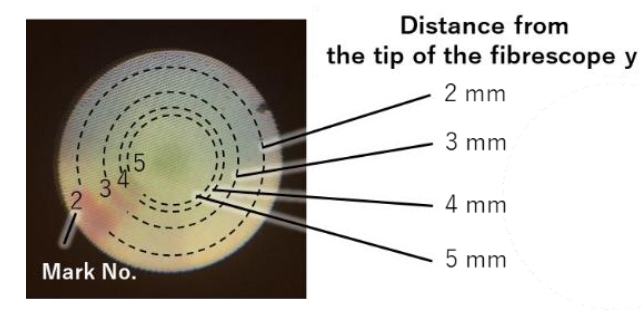

c) Observation of tube using fibrescope

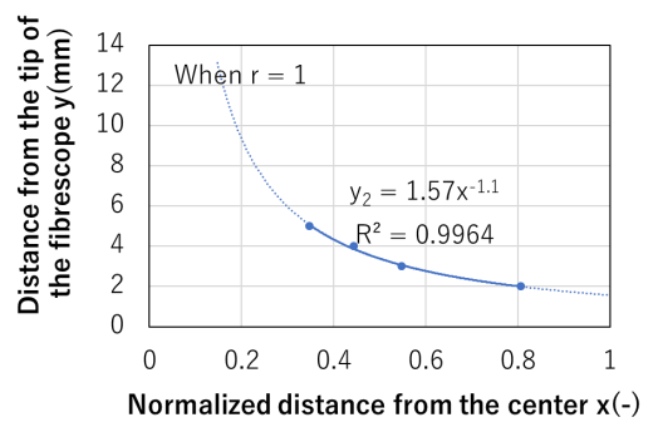

d) Relationship of $x$ and $y$ obtained from Figure $2 b$

Figure 2. Determining distance from tip of fibrescope to coloration boundary

$$
y=\frac{r-0.3 x}{\tan \theta}
$$

The relationship between $x$ and $\theta$ depends on the shape of the lens, and it is independent of $y$ and $r$. To obtain the relationship between $x$ and $\theta$, the fibrescope is inserted into a tube with an outer diameter of $2 \mathrm{~mm}$ with marks at an interval of $1 \mathrm{~mm}$ from the tip of the fibrescope (Figure $2 \mathrm{~b}$ ). Then, the view through the fibrescope is as shown in Figure 2c. The object closer to the tip of the fibrescope appears in the position away from the centre within the circular field of view. In Figure 2c, the circle drawn with a dotted line shows the position where objects at $2 \mathrm{~mm}, 3$ $\mathrm{mm}, 4 \mathrm{~mm}$, and $5 \mathrm{~mm}$ away from the tip of the fibrescope appear in the field of view. From Figure 2c, the relationship between the distance from the tip of the fibrescope to the object, and the normalized distance from the centre, can be plotted as shown in Figure $2 \mathrm{~d}$. The distance $y$ $(\mathrm{mm})$ from the tip of the fibrescope to the object, and the normalized distance from the centre $x[-]$ are approximated with high accuracy within the range of $2 \leqq y \leqq 5$ as follows:

$$
y=1.57 x^{-1.1} ; r=1
$$

By substituting $r=1$ into Eq. (2) and coordinating with Eq. (3), the relationship between $\theta$ and $x$ can be obtained as follows:

$$
\tan \theta=\frac{1-0.3 x}{1.57 x^{-1.1}}
$$

From Eqs. (2) and (4), the relationship between $y$ and $x$ at an arbitrary $r$ can be expressed as follows: 


$$
y=\frac{r-0.3 x}{1-0.3 x} \cdot 1.57 x^{-1.1}
$$

The distance $y(\mathrm{~mm})$ from the tip of the fibrescope to the colouring boundary is determined with a resolution of $0.5 \mathrm{~mm}$ using Eq. (5), when the coloration boundary is observed in the drill hole through the fibrescope.

\section{SPECIMEN}

Concrete and mortar specimens were used for the neutralization depth and $\mathrm{Cl}^{-}$penetration depth measurement. Table 1 shows the information regarding the used specimens. Morl and Conc1 were used to investigate the neutralization depth measurement, while Conc 2 and Conc 3 were used to investigate the $\mathrm{Cl}^{-}$penetration depth measurement. The curing condition of each specimen was as follows: Morl was kept in a room at $20{ }^{\circ} \mathrm{C}$ and with an average relative humidity of $60 \%$ after demoulding for up to 15 months of material age. All concrete specimens were cured under a sealed condition with mould and wrapping up to 91 days after casting. Then, the wrapping of Conc 1 was removed, demoulded, and kept in the room for up to 40 months of material age. Conc 2 and Conc 3 were dried at 40 and $105^{\circ} \mathrm{C}$, respectively, after demoulding and removing the wrap. Then, they were immersed in $\mathrm{NaCl} 5 \%$ salt water for seven days before being kept in the room for up to 40 months of material age. Conc2 and Conc 3 were immersed in $5 \% \mathrm{NaCl}$ salt water and exhibited a difference in the drying conditions before immersion in salt water, such that there existed a difference in the $\mathrm{Cl}^{-}$penetration depth.

Table 1: Specimen information

\begin{tabular}{|c|c|c|c|c|c|c|c|c|c|c|}
\hline \multirow[b]{2}{*}{$\begin{array}{c}\text { Specimen } \\
\text { name }\end{array}$} & \multirow[b]{2}{*}{$\begin{array}{l}\mathrm{W} / \mathrm{B} \\
(\%)\end{array}$} & \multirow[b]{2}{*}{$\begin{array}{l}\text { s/a } \\
(\%)\end{array}$} & \multicolumn{7}{|c|}{ Unit content $\left(\mathrm{kg} / \mathrm{m}^{3}\right)$} & \multirow[b]{2}{*}{ Specimen size $[\mathrm{mm}]$} \\
\hline & & & Water & OPC & Flyash & Blust Furnace Slug & Sand & Gravel & $\mathrm{AE}$ & \\
\hline Mor & 60 & 100 & 297 & 248 & 0 & 248 & 1,310 & 0 & 0.62 & Rectangular $(100 \times 100 \times 50)$ \\
\hline Conc1 & \multirow{3}{*}{50} & \multirow{3}{*}{45} & \multirow{3}{*}{175} & \multirow{3}{*}{175} & \multirow{3}{*}{140} & \multirow{3}{*}{35} & \multirow{3}{*}{780} & \multirow{3}{*}{968} & \multirow{3}{*}{0.88} & \multirow{3}{*}{ Cylinder $(\mathrm{D} 100 \times \mathrm{H} 200)$} \\
\hline Conc2 & & & & & & & & & & \\
\hline Conc3 & & & & & & & & & & \\
\hline
\end{tabular}

\section{DRILLING PROCESS}

Cleaning the drill holes is important in making the coloration occur correctly on the drill hole. The ease of cleaning was compared for the dry drilling and wet drilling cases. After dry drilling or wet drilling had been completed on the concrete specimen (Conc3), the drill hole was rubbed ten times using a brush under running water. Then, the specimen was cut across the drill hole as shown in Figure 3, where the edge of the drill hole is emphasized by being traced with a red pencil. The drilling mud was removed from the hole after the dry drilling, but remained in the hole after the wet drilling. Because the dry drilling makes it easier to clean the interior of the hole, in this study, dry drilling was carried out to easily remove the drilling mud by cleaning with a brush to obtain a clear coloration. 


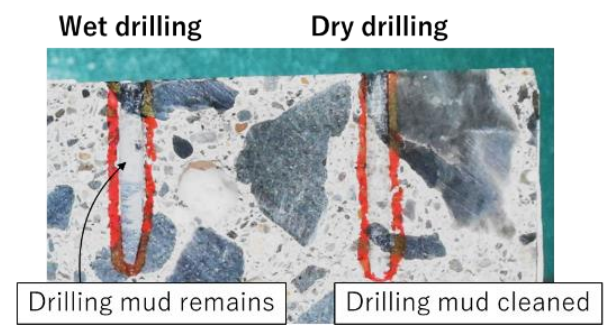

Figure 3. Drill hole surface after wet drilling and after dry drilling

\section{NEUTRALIZATION DEPTH MEASUREMENT}

\section{Coloration Investigation}

\section{(1) Effect of Surface Drying Extent on Coloration}

Izumi et al. (1988) reported that it is important for the surface to be in a dry state to obtain a clear coloration with a phenolphthalein solution. However, the reported cases are limited and there is no specific description regarding the effect of the drying extent on the sharpness of the coloration boundary. Therefore, the following experiment was conducted to investigate an appropriate drying degree, when phenolphthalein was sprayed to obtain a clear coloration. Table 2 shows the experimental parameters. The mortar specimen (Mor) was cut to small samples, and the surface was wetted with water or ethanol. The samples were dried until the surface turned white by drying or until $1 \mathrm{~min}$ had elapsed since the surface turned white. Wetting the surface with liquid before drying was assumed to be a process of cleaning the wall surface with water or ethanol after drilling. Drying was performed using a 1,000 W dryer, and hot air was provided from a position of $10 \mathrm{~cm}$ away from the sample. The results are presented in Figure 4. The contrast of the coloration boundary was most clear in case (E2), where the surface was wetted with ethanol and dried until $1 \mathrm{~min}$ had elapsed since the surface turned white. In this case, it can be said that the surface was the driest amongst the four cases because ethanol is more volatile than water, and because drying continued after whitening. Therefore, this result reveals that sufficient drying is necessary to obtain a clear coloration boundary, as has also been reported by Izumi et al. (1998). However, the boundary was ambiguous in the series of E1 and W1, wherein the indicator was sprayed immediately after the wet colour disappeared on the surface, and the surface turned white, which is different from a previous report, according to

Table 2: Cases investigated to clarify the effect of drying extent on coloration

\begin{tabular}{|c|c|c|c|}
\hline & & \multicolumn{2}{|c|}{$\begin{array}{l}\text { The timing when phenolphthalein solution is } \\
\text { sprayed }\end{array}$} \\
\hline & & $\begin{array}{l}\text { Imidiately after the } \\
\text { surface turned white }\end{array}$ & $\begin{array}{l}\text { Drying for } 1 \text { min after the } \\
\text { surface turned white }\end{array}$ \\
\hline \multirow{2}{*}{$\begin{array}{c}\text { A liquid that wets } \\
\text { the surface before } \\
\text { drying }\end{array}$} & Ethanole & E1 & E2 \\
\hline & Water & W1 & W2 \\
\hline
\end{tabular}
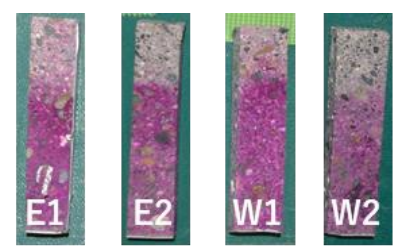

Figure 4. Coloration result with different surface drying extent

which the coloration was clear when the indicator was sprayed onto the dried surface (Izumi et 
al., 1988). From the abovementioned result, it was assumed that the coloration becomes clear when the phenolphthalein solution is sprayed after drying continues for a while, even after the wet colour disappears from the surface.

\section{(2) Effect of Phenolphthalein Solution Spraying Amount on Coloration}

It is recommended to spray the phenolphthalein solution with such amount that droplets are not formed to prevent colour blur (JIS A 1152). However, when the phenolphthalein solution is sprayed toward a tiny drill hole, colour blur is likely to occur because droplets are easily formed in the narrow hole, and the interior of the hole is filled with the phenolphthalein solution. To investigate the effect of the spraying amount and surface condition, the coloration was investigated in six cases, as presented in Table 3, wherein the dry state of the surface before spraying the phenolphthalein solution and the spraying amount were changed. Here, small samples taken from the mortar specimen (Mor) were used. In the "Dry" series, the surface was wetted with water, then dried using a dryer after $3 \mathrm{~min}$ had elapsed since the surface whitened. In the "Wet" series, the surface was wetted with water until the gloss could not be observed. The spraying amount of the phenolphthalein solution was as follows: spray until a region that was not wet by the solution remained; spray until the entire area is wet, but gloss is not observed; spray until the droplets fall from the surface. Each spraying amount was approximately 2, 5, and $20 \mathrm{mg} / \mathrm{cm}^{2}$, respectively. Figure 5 shows the coloration results. In the case of the "Wet" series, colour blur was observed even if the amount of the phenolphthalein solution was small, and the boundary between the coloured area and the non-coloured area was ambiguous. In the "Dry" series, clear boundaries were obtained without colour blur, even if the sprayed amount of the phenolphthalein solution was large, as in the case of "Dry 3". Therefore, it was concluded that a clear coloration boundary can be obtained when the wall surface has been sufficiently dried, even in the case wherein a tiny drill hole, which is easily filled with the phenolphthalein solution, is used.

Table 3 : Cases investigated to clarify the effect of phenolphthalein solution spraying amount on coloration

\begin{tabular}{|c|c|c|c|c|}
\hline & \multicolumn{3}{|c|}{$\begin{array}{c}\text { Spray amount of the } \\
\text { phenolephtalein }\left(\mathrm{mg} / \mathrm{cm}^{2}\right)\end{array}$} \\
\hline & & 2 & 5 & 20 \\
\hline \multirow{2}{*}{$\begin{array}{c}\text { Dry } \\
\text { condition }\end{array}$} & Wet & Wet1 & Wet2 & Wet3 \\
\hline & Dry & Dry1 & Dry2 & Dry3 \\
\hline
\end{tabular}

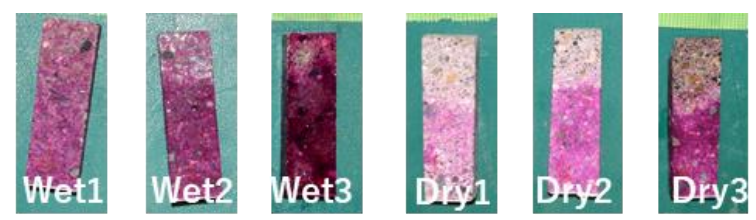

Figure 5. Coloration result for different spraying amounts

\section{Experiment on Coloration of $1 \mathrm{~mm}$ Drill Hole}

Next, the drying time needed to obtain a clear coloration by the phenolphthalein solution was investigated for an actual drill hole with a diameter of $1 \mathrm{~mm}$ along the flow shown in Figure 6. Six small samples were prepared from the mortar specimen (Mor), and holes with a diameter of $1 \mathrm{~mm}$ were drilled into a depth of approximately $30 \mathrm{~mm}$. Then, the drill holes were washed using ethanol and a brush, and different drying conditions were applied. The drying cases were as follows: drying was carried out for (a) $1 \mathrm{~min}$, (b) $5 \mathrm{~min}$, (c) $7 \mathrm{~min}$, or (d) $10 \mathrm{~min}$ using a dryer at a position of $10 \mathrm{~cm}$ away from the sample; drying was carried out by exposure to air for (e) 1 day or (f) 7 days after washing. After drying, the phenolphthalein solution was sprayed into the drill hole (Figure 6A). Then, the samples were cut along the drill hole, and the phenolphthalein solution was sprayed onto the cut surface to colour the surface differently to the drill hole (Figure 6B). The coloration on the wall surface of the drill hole was compared with the coloration on the cutting surface. Figure 7 shows the coloration results. As can be seen, 
the edges of the drill holes are emphasized with white dotted lines. For the samples that were dried with a dryer for $1 \mathrm{~min}$ (Figure 7a), $5 \mathrm{~min}$ (Figure 7b), and $7 \mathrm{~min}$ (Figure 7c), the coloration boundary was unclear, attributed to the occurrence of colour blur. Insufficient drying is the probable cause of the colour blur, based on the preceding results obtained in Figures 4 and 5. For the sample that was dried for $10 \mathrm{~min}$ (Figure 7d) and the samples exposed to air for 1 day (Figure 7e) or 7 days (Figure 7f), a clear coloration boundary was obtained on the drill wall surface, and the boundary position in the drill wall surface agreed with that of the cutting surface. Therefore, in these three cases, it can be said that sufficient drying was provided for the $1 \mathrm{~mm}$ drill hole.

According to the experiment above, it was confirmed that preferable coloration appears even on a drill hole with a diameter of $1 \mathrm{~mm}$, as long as the surface is sufficiently dry. The procedure to achieve sufficient drying of the drill wall surface was as follows: dried for 10 minutes with a hairdryer, or dried by exposure to the air for 1 day or more.

(A)

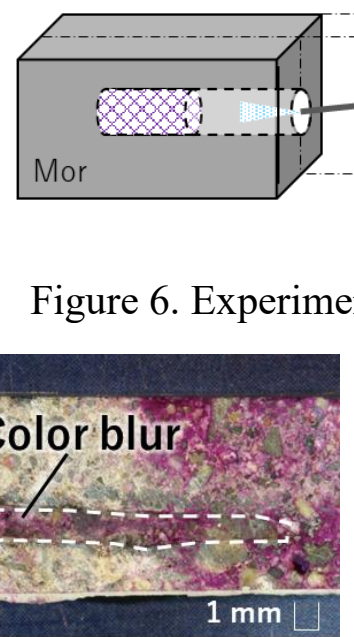

a) 1 min drying by hairdryer

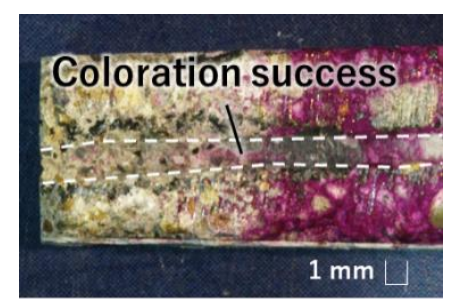

d) 10 min drying by hairdryer
(B)

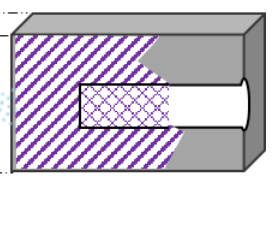

Phenolephthalein
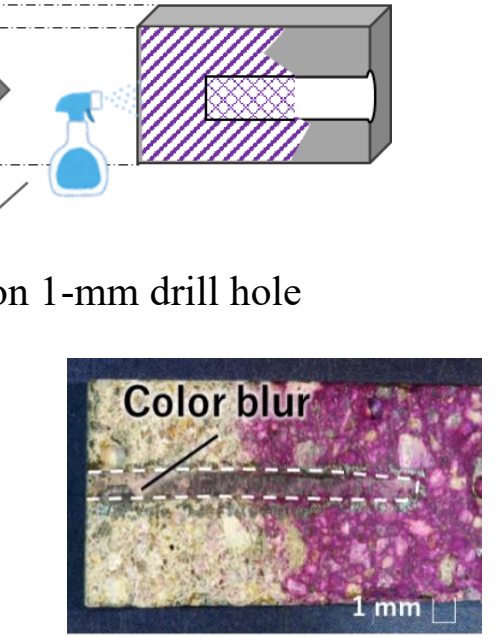

b) 5 min drying by hairdryer

c) 7 min drying by hairdryer

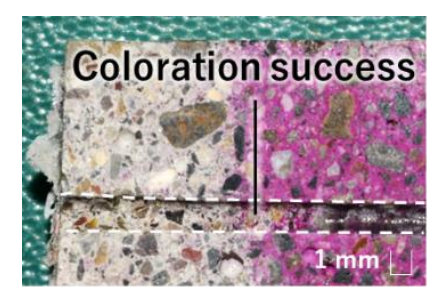

e) 1-day exposure to air

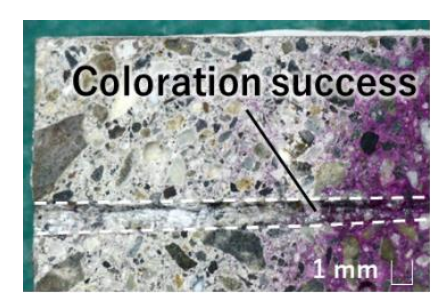

f) 7-day exposure to air

Figure 7. Coloration results under six different drying conditions

\section{Verification of Neutralization Depth Measurement by Fibrescope}

The neutralization depth measurements by the drill hole with a diameter of $1 \mathrm{~mm}$ and the fibrescope was verified with a mortar specimen (Mor) and concrete specimen (Conc1). Various $1 \mathrm{~mm}$ holes were drilled into the surface of the specimens, and these drill holes were washed using ethanol and a brush until the aggregate on the drill wall became clearly visible. Then, they were dried with a $1,000 \mathrm{~W}$ dryer for $10 \mathrm{~min}$ from a position of $10 \mathrm{~cm}$ away from the specimens. Here, the drying time was determined based on the preliminary experiment shown in Figure 7. 
Then, the phenolphthalein solution was sprayed into the drill hole, and the interior of the drill hole was observed using the fibrescope. Additionally, the neutralization depth was measured using Eq. (1), when the coloration boundary was observed. Figure 8 shows an example of a non-coloured part and a coloured part observed through the fibrescope. Subsequently, the specimen was cut along the drill holes, and the phenolphthalein solution was sprayed onto the cutting surface. Additionally, the neutralization depth at each drill hole location was measured using a calliper with a resolution of $0.5 \mathrm{~mm}$, and the result was compared with the result obtained using the fibrescope. Figure 9 shows the comparison of the neutralization depth measured by the two methods. The results obtained by the two measurement methods are in good agreement with a standard error of $0.37 \mathrm{~mm}$, and have higher accuracy than the results obtained by previous studies with a standard error of $0.96 \mathrm{~mm}$, wherein a drill with a diameter of $14.5 \mathrm{~mm}$ and an endoscope with a diameter of $12.9 \mathrm{~mm}$ were used (Harada et al., 2007). Additionally, the validity of the definition of the neutralization depth expressed by Eq. (1) was ensured for the $1 \mathrm{~mm}$ drill hole. Finally, it was confirmed that the neutralization depth could be measured with high accuracy, even with a $1 \mathrm{~mm}$ drill hole and a $0.6 \mathrm{~mm}$ fibrescope, when the drill hole had dried sufficiently.

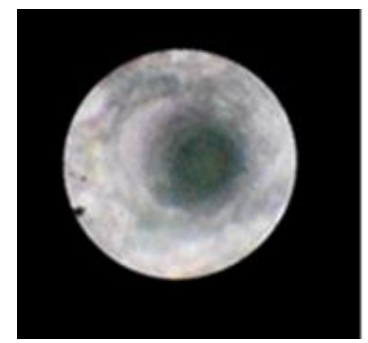

(a) Non-coloured part

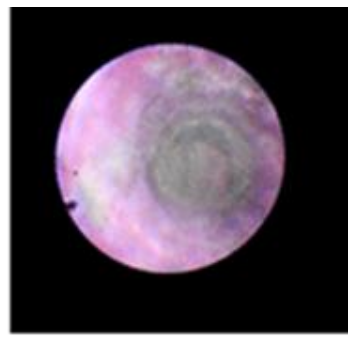

(b) Coloured part

Figure 8. Coloration of $1 \mathrm{~mm}$ drill hole with phenolphthalein solution observed through fibrescope

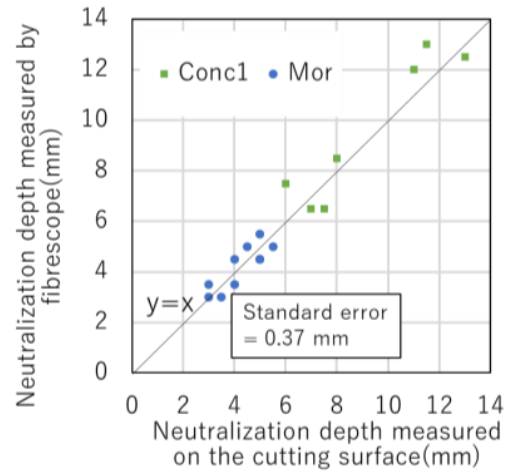

Figure 9. Comparison of neutralization depth measured using fibrescope with neutralization depth measured on cutting surface

\section{CHLORIDE ION PENETRATION DEPTH MEASUREMENT}




\section{Coloration Investigation}

\section{(1) Effect of Surface Drying Extent on Coloration}

The effect of the concrete surface's drying extent on the coloration after spraying with silver nitrate was investigated. Two small samples were prepared from the concrete specimen (Conc2), and subjected to different surface drying extent. Specifically, one of the samples was wetted with water and then dried until the gloss could not be observed, whereas the wet colour could be uniformly observed. The other sample was wetted with water and dried using a dryer until $10 \mathrm{~min}$ had passed after the surface whitened by drying. Figure 10 shows the coloration results. In both cases, the white coloration and yellow-brown coloration were obvious. In the specimens used in this occasion, clear coloration was observed regardless of whether the surface was dry or wet. However, previous studies have reported that there existed various cases wherein the coloration caused by the silver nitrate did not appear when the concrete was extremely dry (Aoki et al., 2013). Therefore, it is considered that the surface should be wet to ensure a clear coloration by the silver nitrate solution.

\section{(2) Effect of Silver Nitrate Solution Amount on Coloration}

As was discussed in the section titled "Effect of phenolphthalein solution spraying amount on coloration", the effect of the amount of silver nitrate solution on the coloration was investigated. Small samples were taken from the concrete specimen (Conc2), and their surface was wetted with water until gloss was not observed. Then, a silver nitrate solution was sprayed. The spraying amount of the phenolphthalein solution was regulated as follows: spray until a region remains that has not been wetted with solution ("Little" case); spray until the entire area is wet, but gloss is not observed ("Middle" case); spray until the droplets fall from the surface ("Much" case). The spray amount of each case was approximately 2,5 , and $20 \mathrm{mg} / \mathrm{cm}^{2}$. Figure $11 \mathrm{a}$ presents the coloration results when the abovementioned amounts were sprayed. Clear coloration was observed in the "Much" and "Middle" cases. However, in the "Little" case, the coloration was poor and the coloration boundary could not be distinguished. As shown in Figure $11 \mathrm{~b}$, a clear coloration boundary appeared in the "Little" case when spraying an additional 3 $\mathrm{mg} / \mathrm{cm}^{2}$. From this experiment, it was found that the spray amount of the silver nitrate solution did not make much difference on the coloration, although it is possible that the coloration became poor when the spraying amount was too small. In such case, however, additional spraying made the coloration clearer.

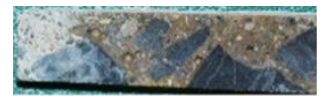

Much

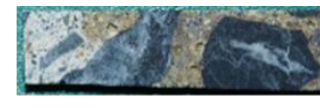

Middle

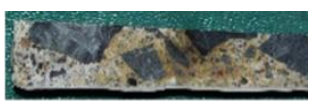

Little

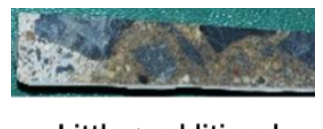

Little + additional

b) After additional spraying in "Little" case

a) When predetermined amount was sprayed

Wet

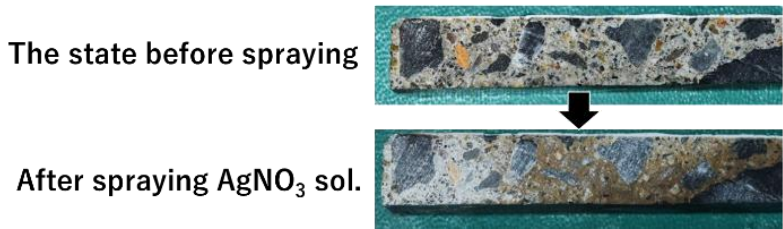

Dry

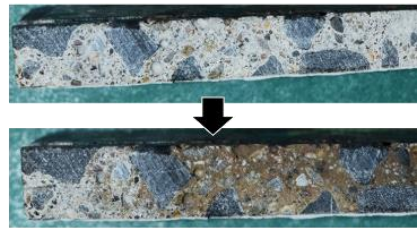

Figure 10. Coloration results under different surface drying extent 
Figure 11. Coloration results with different spraying amounts of silver nitrate solution

\section{Coloration of 2 mm Drill Hole}

It was confirmed that the appropriate coloration was obtained on the surface of a drill hole with a diameter of $2 \mathrm{~mm}$. The reason for using a drill hole with a diameter of $2 \mathrm{~mm}$ is stated in the next section. The following procedure was carried out based on the following result: for a clear coloration, it is better that the surface is wet but the spraying amount is not important (Figures 10 and 11). Three small samples were prepared from the concrete specimen (Conc2), and holes with a diameter of $2 \mathrm{~mm}$ were drilled into a depth of approximately $30 \mathrm{~mm}$. The drill holes were washed with water and brushed, and water filled into the drill hole was aspirated with a dropper as much as possible. Then, a silver nitrate solution was sprayed into the drill hole. At this time, a white coloration part and a yellow-brown coloration part were observed through the fibrescope, as shown in Figure 12. Next, the samples were cut along the drill holes, and a silver nitrate solution was sprayed onto the cutting surface to make the coloration comparable with the coloration on the drill wall. Figure 13 presents the coloration results. White coloration and yellow-brown coloration could be obtained on the drill wall surface, and the boundary location on the drill wall surface agrees with that of the cutting surface. Thus, it was confirmed that the above procedure gives a clear coloration with a silver nitrate solution on the $2 \mathrm{~mm}$ drill wall surface.

\section{Suitable Distance from Target to Observe Colour Using Fibrescope}

The procedure of colouring with a silver nitrate solution also worked well in a drill hole with a diameter of $1 \mathrm{~mm}$, as shown in Figure 14. However, as shown in Figure 15, a difference in colour could not be observed when the fibrescope was inserted into the A and B positions (Figure 14) before cutting the specimen. The fibrescope provided light from the optical fibres extending to the tip. Therefore, if the distance to the object was too close, the amount of reflected light increased and this made it difficult to distinguish the exact colour of the object. For example, the concrete surfaces with different coloration, shown as A, B, C, and D in Figure $16 \mathrm{a}$, were observed from the front of the surface through a fibrescope at a distance of $1 \mathrm{~mm}$ or $2 \mathrm{~mm}$ from the surface to the tip of the fibrescope. Figure $16 \mathrm{~b}$ shows the results of the observation. The colour difference between A and B, which had been coloured by the silver nitrate solution, could be observed when the distance was $2 \mathrm{~mm}$. However, it could not be observed when the distance was $1 \mathrm{~mm}$, owing to the reflection of white light. Moreover, the colour difference between $\mathrm{C}$ and $\mathrm{D}$, which had been coloured by the phenolphthalein solution, could be observed when the distance was $1 \mathrm{~mm}$ and when the distance was $2 \mathrm{~mm}$. The difference in the coloration that resulted from the silver nitrate solution became difficult to observe, owing to the reflection of white light when the fibrescope was set close to the object. Thus, it was impossible to observe a coloration difference in the $1 \mathrm{~mm}$ hole, where the amount of the

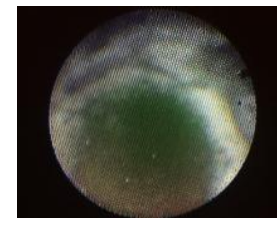

(a) White coloration part

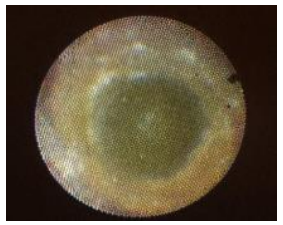

(b) Yellow-brown coloration part

Figure 12. Coloration of $2 \mathrm{~mm}$ drill hole with silver nitrate solution observed through fibrescope
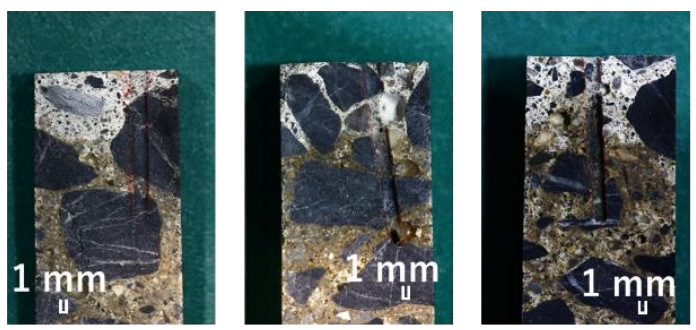

Figure 13. Coloration results of $2 \mathrm{~mm}$ drill hole with silver nitrate solution 
reflected light increased.

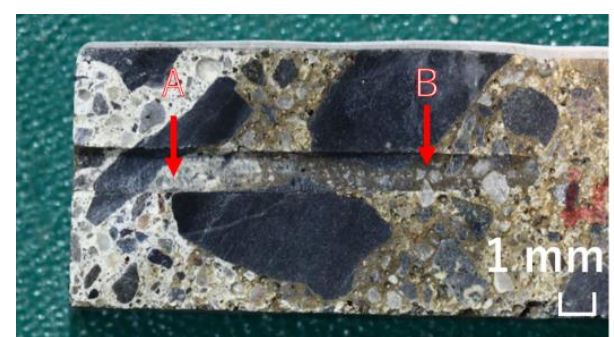

Figure 14. Coloration on $1 \mathrm{~mm}$ drill hole

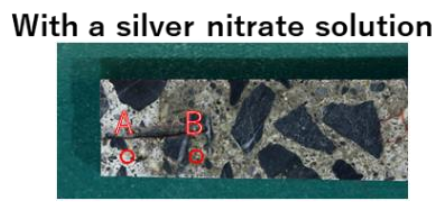

With a phenolphthalein solution

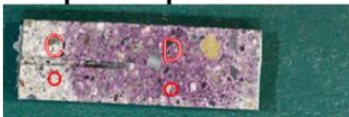

a) Specimens coloured with indicators

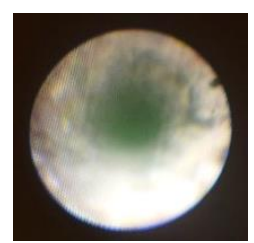

White coloration part

(A)

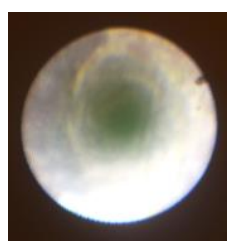

Yellow-brown coloration part (B)

Figure 15. Coloration observed in $1 \mathrm{~mm}$ drill hole using fibrescope

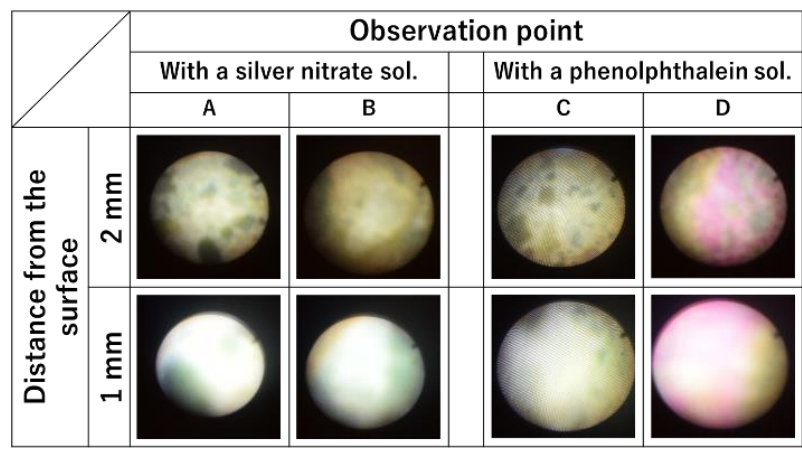

b) Observation results

Figure 16. Colour observed through fibrescope changes with distance from target

\section{Verification of Chloride Ion Penetration Depth Measurement Using Fibrescope}

The $\mathrm{Cl}^{-}$penetration depth measurement by the drill hole with a diameter of $2 \mathrm{~mm}$ and the fibrescope was verified using the concrete specimens (Conc2 and Conc3). Various $2 \mathrm{~mm}$ holes were drilled from the surface of the specimens, and coloured according to the procedure described above. Additionally, the interior of the drill hole was observed using the fibrescope, and the $\mathrm{Cl}^{-}$penetration depth was measured using Eq. (1) when the coloration boundary was observed. Subsequently, the specimen was cut along the drill holes, and the silver nitrate solution was sprayed onto the cutting surface. Additionally, the $\mathrm{Cl}^{-}$penetration depth at the location of each drill hole was measured using a calliper with a resolution of $0.5 \mathrm{~mm}$. The result was compared with the result obtained by the fibrescope. Figure 17 shows the comparison of the $\mathrm{Cl}^{-}$penetration depth measured by the two methods. The results obtained by the two measurement methods are in good agreement with a standard error of $0.29 \mathrm{~mm}$. Thus, it was confirmed that the $\mathrm{Cl}^{-}$penetration depth could be measured with high accuracy, even when using a $2 \mathrm{~mm}$ drill hole and a $0.6 \mathrm{~mm}$ fibrescope, when the proposed procedure was performed. Moreover, the validity of the neutralization depth definition shown in Eq. (1) was ensured for the $2 \mathrm{~mm}$ drill hole. 


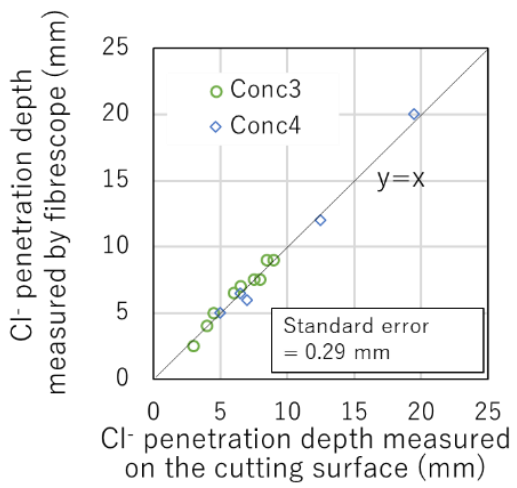

Figure 17. Comparison of $\mathrm{Cl}^{-}$penetration depth measured using fibrescope with that measured on cutting surface

\section{CONCLUSION}

The distance in the depth-direction along the drill hole could be measured by the proposed equation, when a fibrescope with a diameter of $0.6 \mathrm{~mm}$ was used. When spraying the phenolphthalein solution onto the concrete surface to measure the neutralization depth, it was necessary to sufficiently dry the surface before spraying to obtain a clear coloration. Additionally, the colour blur was alleviated, even with a large spray amount, as long as the surface was sufficiently dry. To sufficiently dry a hole with a diameter of $1 \mathrm{~mm}$, for example, it is preferable to dry the hole using a dryer for $10 \mathrm{~min}$, or by exposing it to air for one day or more after cleaning the hole with ethanol. The neutralization depth measured using the fibrescope and the $1 \mathrm{~mm}$ drill hole had high accuracy with a standard error of $0.37 \mathrm{~mm}$ in the result measured using a calliper on the cutting surface.

When spraying a silver nitrate solution onto the concrete surface to measure the $\mathrm{Cl}^{-}$penetration depth, the wet surface obtained a clear coloration, while the spray amount did not make much difference. In the drill hole with a diameter of $1 \mathrm{~mm}$, white coloration and yellow-brown coloration could not be observed owing to the reflection of white light. However, in the case of a hole with a diameter of $2 \mathrm{~mm}$, the distinction was possible. The $\mathrm{Cl}^{-}$penetration depth measured using the fibrescope and the $2 \mathrm{~mm}$ drill hole had high accuracy with a standard error of $0.29 \mathrm{~mm}$ in the result measured using callipers on the cut surface.

In future work, a method of suppressing the reflection of light to clearly distinguish the colours inside a small drill hole will be investigated, such that the chloride ion penetration depth and neutralization depth can be measured, even with smaller drill holes than those used in this study. Additionally, a quick method for filling holes that utilize the small diameter will also be investigated.

\section{ACKNOWLEDGEMENT}

This study was financially supported by the Sumitomo Electric Group.

\section{REFERENCES}

RILEM CPC18 (1988). "Measurement of hardened concrete carbonation depth" Materials and Structures, Vol.21, No.126, pp.453-455. 
Otsuki, N., Nagataki, S. and Nakashita, K (1993). "Evaluation of the AgNO3 solution spray method for measurement of chloride penetration into hardened cementitious matrix materials" Construction and Building Materials, Vol.7, No.4, pp.195-201.

Aoki, Y., Shimano, K., Miyoshi, Y. and Suzuki, M. (2008). "Estimation of chloride ion penetration to hardened concrete by AgNO3 solution spray method" Proceedings of the Japan Concrete Institute, Vol.30, No.1, pp.759-764.

He, F., Shi, C., Yuan, Q., Chen, C. and Zheng, K. (2012). "AgNO3-based colorimetric methods for measurement of chloride penetration in concrete" Construction and Building Materials, Vol.26, No.1, pp.1-8.

He, F., Shi, C., Yuan, Q., An, X. and Tong, B. (2011). "Calculation of chloride concentration at color change boundary of AgNO3 colorimetric measurement" Cement and Concrete Research, Vol.41, No.11, pp.1095-1103.

Kim, M. Y., Yang, E. I., and Tae, S.Yi. (2007). "Evaluation of Chloride Penetration Characteristics using a Colorimetric Method in Concrete Structures in Concrete Structures" Proceedings of Structural Mechanics in Reactor Technology, Toronto, Canada, 2007, Paper\#DH01/4, pp.1-6.

Kasai, Y. and Yuasa, N. (1998). "The Neutralization of Concrete and the Proposal of Rapid Testing Method for Its Depth" Journal of the Japanese Society for Non-Destructive Inspection, Vol.47, No.9, pp.643-648.

Nihira, T., Sogabe, M., tanimura, Y. and Higasikawa, K. (2004). "Feasibility study on the neutralization depth measurement by drill method in concrete structure" Proceedings of the Japan Concrete Institute, Vol.26, No.1, pp.2025-2030.

Sawamoto, T., Fujiwara, T., Yuasa, N. and Kasai, Y. (2010). "A study on simple method for measurement of chloride penetration depth of concrete by combining drilling powder with silver nitrate solution" Cement Science and Concrete Technology, Vol.64, No.1, pp.196-202.

Harada, K. and Ito, Y. (2007). "Development of endoscope for concrete structure inspection" Technical report of NISHIMATSU CONSTRUCTION Co., Ltd., Vol.30, No.20, pp.109110.

Yamamoto, D., Hamada, H., Sagawa, Y. and Ikeda, T. (2009). "Development of diagnostic method for deterioration of sewage pipe by semi-destructive method" http://www.kyugikyo.com/pdf/h21/02.pdf, (refer on Nov. 14th, 2018).

Ito, Y., Takahashi, Y. and Miyamoto, N. (2007). "Development of stick scanner for concrete structure inspection" Kensetsunosekoukikaku Oct. 2007, pp.19-24.

Zacoeb, A., Ito, Y. and Ishibashi, K. (2012). "Internal crack assessment on concrete structures by scanning image analysis" ARPN Journal of Engineering and Applied Sciences, Vol.7, No.8, pp.939-944.

Harada, K., Ito, Y. and Miyamoto, N. (2009). "Development of evaluation method of concrete structure by stick scanner" Technical report of NISHIMATSU CONSTRUCTION Co., Ltd., Vol.32, No.17, pp.97-98.

Izumi, I., Oshida, F. and Kasami, H. (1988). "Study on standardization of neutralization test method" Proceedings of the Japan Concrete Institute, Vol.10, No. 2.

Aoki, Y., Sawamoto, T. and Shimano, K. (2013). "Report on several empirical knowledge on chloride ion penetration depth measurements by silver nitrate solution spraying method" Proceedings of the Japan Concrete Institute, Vol.35, No.1, pp.1843-1848. 
Kothari, A., Newman, B. N. and Kuikarni, D. (2006). "Breast duct micro-endoscopy: A study of technique and a morphological classification of endo-luminal lesions" The Breast, Vol.15, No.3, pp.363-369. 